\title{
WSN for Traffic Monitoring using Raspberry Pi Board
}

\author{
Michal Kochláň, IEEE Student Member \\ University of Žilina \\ Faculty of Management Science and Informatics \\ Univerzitná 8215/1, 01026 Žilina, Slovakia \\ Email: michal.kochlan@fri.uniza.sk
}

\author{
Michal Hodoň, Lukáš Čechovič, \\ Ján Kapitulík, Matúš Jurečka \\ University of Žilina \\ Faculty of Management Science and Informatics \\ Univerzitná 8215/1, 01026 Žilina, Slovakia \\ Email: \{michal.hodon, lukas.cechovic, jan.kapitulik, \\ matus.jurecka\}@fri.uniza.sk
}

\begin{abstract}
This paper introduces low-cost non-intrusive sensory that can collect traffic data based on Raspberry Pi single board computer. Image information acquired by Raspberry Pi HD camera module is analyzed for moving objects presence. After evaluation of detected object count, size, class and motion vector object properties are sent to server node by RF transceiver. Sensor low-power consumption ensures possibility to operate from battery for an extended period of time.
\end{abstract}

\section{INTRODUCTION}

$\mathbf{T}$ RAFFIC flow monitoring and analysis has been active research and engineering topic for more than two decades. Main information acquired from traffic flow monitoring includes: traffic volume, vehicle type identification (bike, car, light van, truck) and vehicle speed. Traffic volume data is used for a variety of purposes including historical trend analysis, forecasting, planning for future infrastructure improvements and expansions. Whereas transport remains the largest producer of $\mathrm{CO}$ emissions in EU, traffic monitoring becomes important also from the environmental point of view [1]. Also the World Health Organization has officially decreed that inhaling diesel fumes can cause lung cancer and puts diesel plumes in the same category as arsenic, strontium-90 and neutron radiation. [2] This has given traffic monitoring significant importance.

Other traffic data parameters, such as speed and vehicle classification, are becoming more important as a measure of traffic safety and roadway pavement use. Recent traffic flow analysis systems are able to perform vehicle number plate recognition which can provide information about main ways of traffic flow through cities and can help to optimize road infrastructure. Collecting this data can be done using a variety of different technologies. Traffic detection technology methods scoring biggest interest in this area includes: Doppler radar (measures the relative velocity of an object moving through its target range), magnetometer sensors (detects vehicles based on the disruption of the Earth's magnetic field by metal vehicles), video camera (processes images using sophisticated

This work was supported by Competence Center for research and development in the field of diagnostics and therapy of oncological diseases", ITMS: 26220220153, co-financed from EU sources and European Regional Development Fund computer algorithms), side-fire radar (side-fire beams placed along a roadway reflect back to the sensor to detect vehicles), pneumatic tubes (transmits information to a counting device after a pulse is created when vehicles drive over a tube).

With the advent of powerful single board computers like: OLinuXino, Galileo, PandaBoard, Raspberry Pi, Odroid and others it is possible to design reliable, low-cost traffic monitoring system. Low-power consumption of these boards ensures possibility to operate from car battery for an extended period of time often more than one week.

This paper introduces low-cost non-intrusive option that can collect traffic data based on Raspberry Pi. We have chosen this board for its easy and powerful HD camera handling, good performance to power consumption ratio affordable price and wide community.

\section{SYSTEM OVERVIEW}

Traffic flow monitoring system consists of Raspberry Pi based sensor nodes used for acquisition of image information from environment and their analysis. Traffic flow parameters including volume, speed and vehicle class are then sent to main server via RF transceivers [5]. RF connection offers also configuration and diagnostics of sensor nodes.

The main priorities while designing the traffic flow monitoring sensors were:

- low cost of sensors

- low power consumption of sensors

- high reliability

"Fig. 1" shows complete Raspberry Pi based sensor node including camera module, $12 \mathrm{~V}$ battery $9 \mathrm{Ah}$, stem down $5 \mathrm{~V}$ converter and ARDUPILOT 3DRADIO RF transceiver (without antenna).

Rasberry Pi single board computer offers these key features [3]:

- ARM1176JZF-S core CPU @ $700 \mathrm{MHz}$

- Broadcom VideoCore IV GPU @ $250 \mathrm{MHz}$

- $512 \mathrm{MB}$ (shared with GPU)

- 5Mpix Camera module capable of full HD video @ 30fps

- USB, GPIO, UART, I2C and SPI bus

- $700 \mathrm{~mA}(3.5 \mathrm{~W})$ power rating 


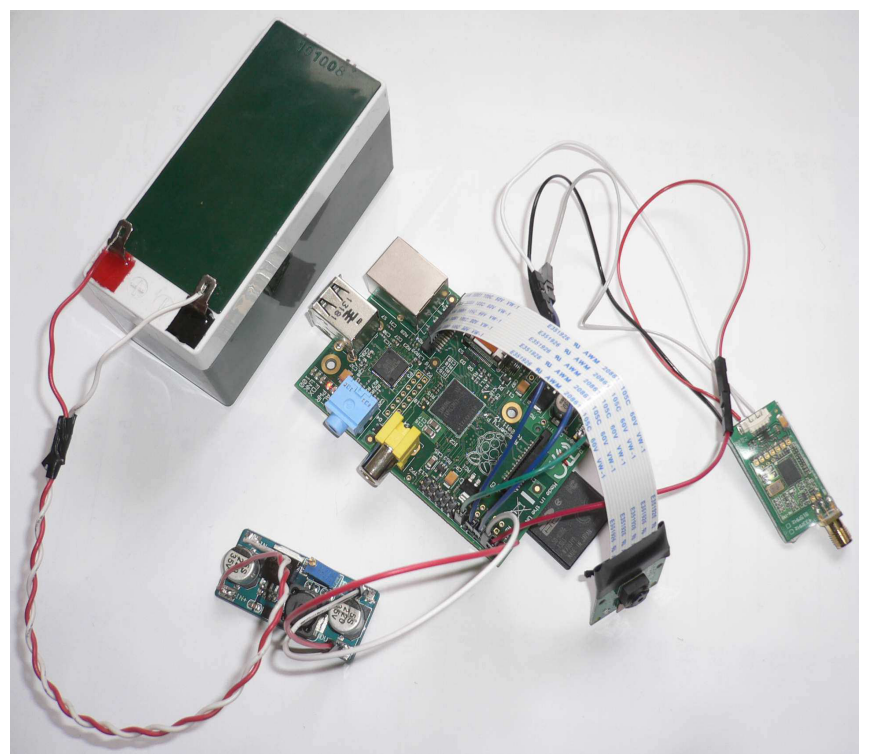

Fig. 1. Raspberry Pi based sensor node

Since processing of high-definition video streams for realtime applications is a challenging task with computationally demanding algorithms it was necessarily to perform as much as possible image processing tasks on GPU. Modern GPUs are very efficient in dealing with computer graphics and their highly parallel structure makes them more effective than general-purpose CPUs for algorithms where processing of large blocks of data is done in parallel.

Raspberry Pi GPU resources can be accessed by MultiMedia Abstraction Layer (MMAL) C library which has been used to implement video data acquisition and processing. Description of the video data processing is shown on "Fig. 2"

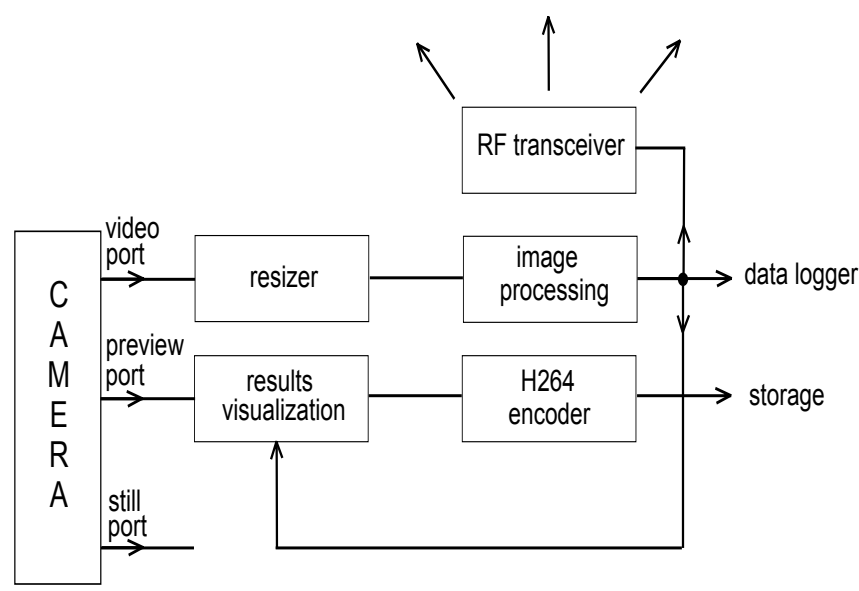

Fig. 2. Video data processing overview

Camera has three output ports (video, preview and still port). Due to the hardware limitations all of these ports must be set to the same resolution, this was in our case $1280 \times 720$ at 30 frames per second. Camera still port was not used.
Since sufficient resolution for reliable vehicle detection is much lower $(640 \times 480$ has been used in our system) image processing block has been connected to camera port through resizer block. The results of image processing - detected vehicles are visualized by modifying (drawing into) data stream flowing from camera preview port. Encoder block provides compression of raw YUV video data stream into H264 steam which is stored on Raspberry PI's SD card. For demonstration of system functionality encoder block can be easily replaced by previewer block. Showing the traffic live stream with recognized results and statistics is then possible through HDMI. Traffic flow statistics are stored on SD card and also send by ARDUPILOT 3DRADIO RF transceiver [7] to monitoring center main server for further evaluation.

\section{IMAGE PROCESSING}

Image processing block ("Fig. 3") performs moving objects detection and classification.

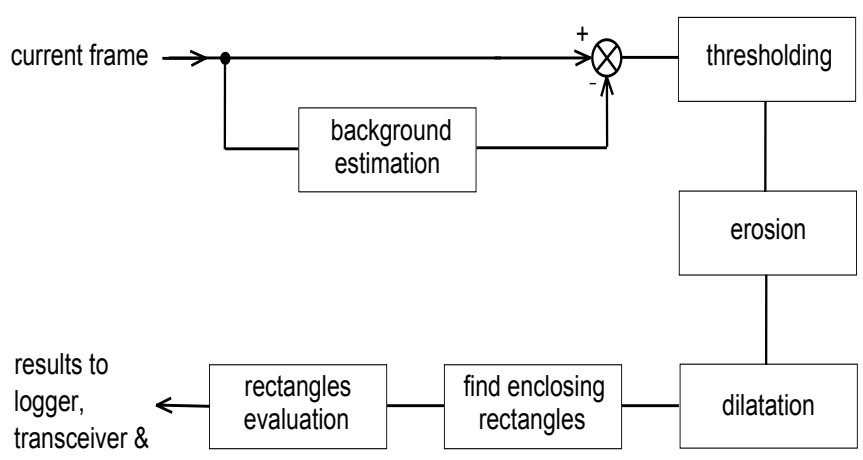

visualizer

Fig. 3. Image processing block overview

The most important procedure in the moving objects detection task is background estimation. Detection of moving objects is made from the difference between the current frame and a reference frame - background image [8]. Background subtraction is a widely used approach for detecting moving objects in videos from static cameras. Our background estimation model is based on the idea that the small changes in frame sequence (e.g. illumination changes) should be retained while relatively fast changes caused by e.g. moving object should be suppressed. Background image is periodically updated according the following equation:

$$
\underline{B}(m)=\underline{B}(m)-f[\underline{F}(m)-\underline{B}(m)]
$$

where $\underline{B}(m)$ and $\underline{F}(m)$ are background and current frame matrices in time $m$, function $f(\cdot)$ can be described by following equation:

$$
f(x)=\frac{\gamma \cdot \frac{x}{\alpha}}{\left[1+\left(\frac{x}{\alpha}\right)^{2}\right]^{2}}
$$


where function argument $x$ is the difference between current frame and background image pixel values, function parameters were set as follows $\alpha=64, \gamma=\frac{25}{2}$.

Graph of function $f(\cdot)$ is shown on "Fig. 4"

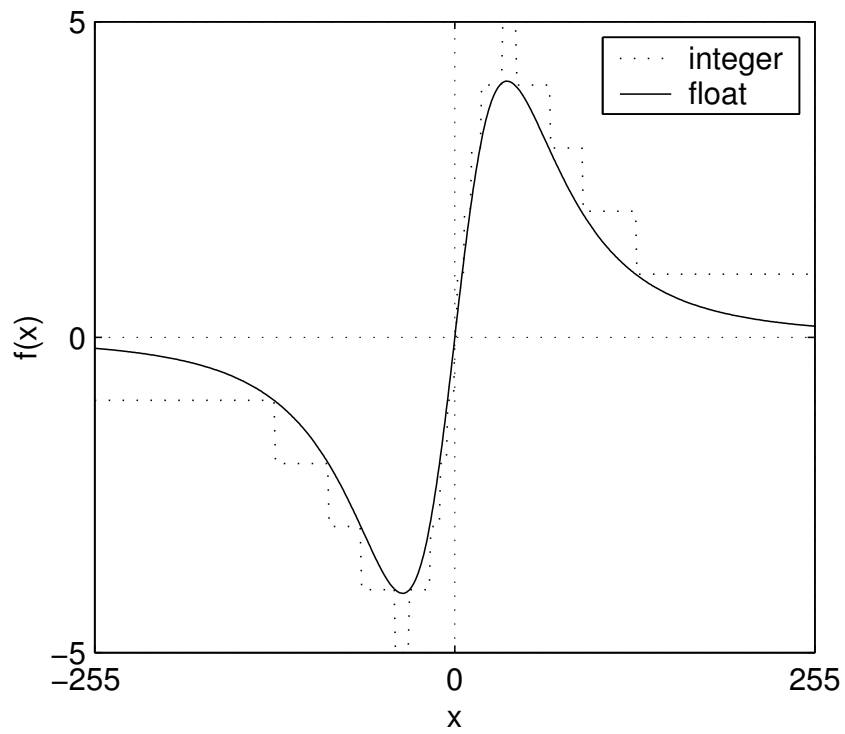

Fig. 4. Image processing block overview

It is clear that the background image function $f(x)$ is raising nearly linear for small $x$ values but for big values of $x$ is decaying.

This background image function has been implemented in integer (shown by dotted line in "Fig.4") which significantly helps to improve speed of whole system.

After subtraction of estimated background image ("Fig.6") from current frame ("Fig.5") the thresholding has been applied so black \& white image has been obtained ("Fig.7").

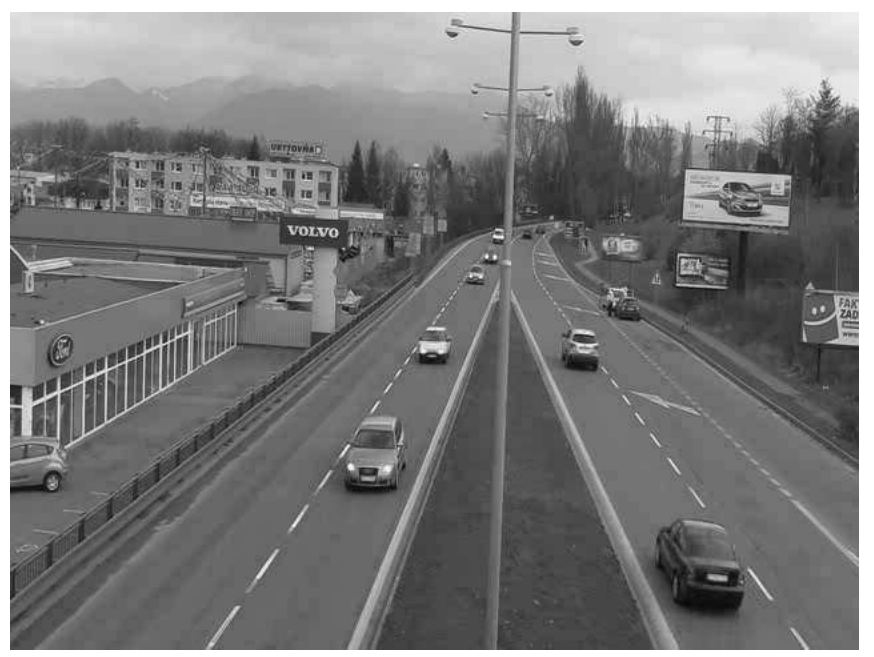

Fig. 5. Original (current) frame

Since most cameras produce a noisy image, motion has been detected in such places, where there is no motion at

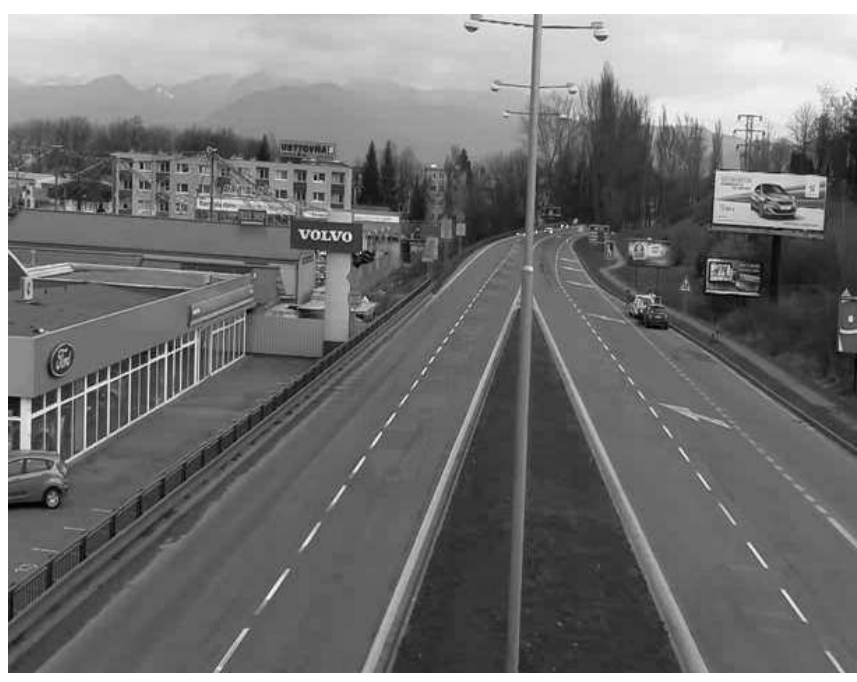

Fig. 6. Background image

all. To remove random noisy pixels, erosion filter followed by dilatation has been used. So the resulting image contains only the regions where the actual motion has been present.

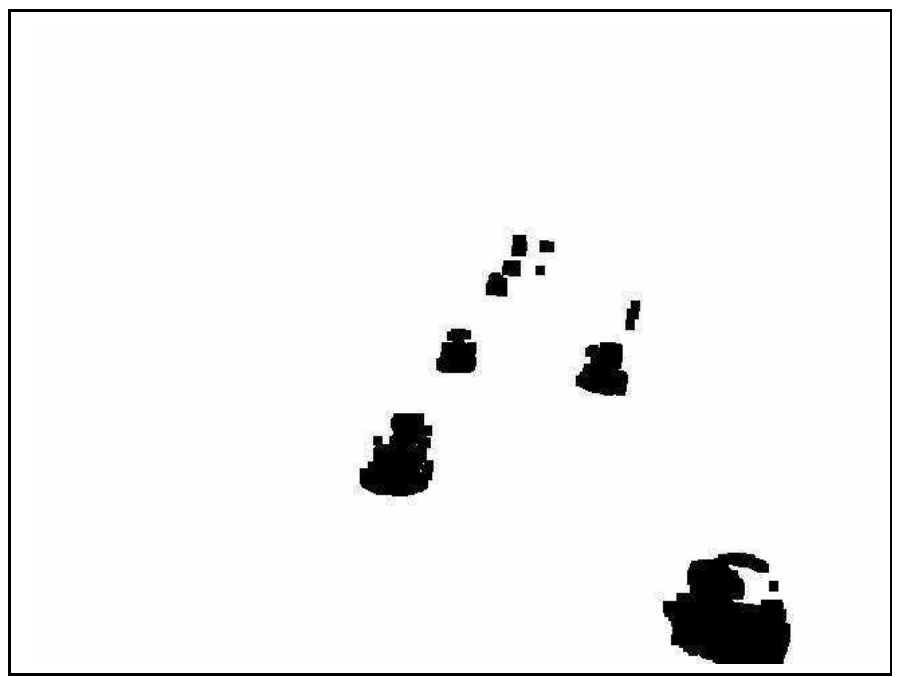

Fig. 7. Image after thresholding

Motion regions are then bounded into minimal enclosing rectangles. These rectangles are then the subject of evaluation where size, position and motion vector is being calculated. Traffic flow informations obtained are stored on SD card, visualized into encoded live video stream ("Fig.9") and transmitted to server node using RF transceiver.

\section{EXPERIMENTS \& RESULTS}

Described sensor node was subject to one day real traffic monitoring test.

It has been attached to the bridge construction over the road and it was monitoring traffic flow in both direction. Power was supplied from $12 \mathrm{~V} 12 \mathrm{Ah}$ rechargeable sealed lead acid battery. 


\begin{tabular}{|c|c|}
\hline feature & recogniton correctnes in [\%] \\
\hline \hline traffic volume & $95.7 \%$ \\
\hline vehicle class & $93.2 \%$ \\
\hline vehicle speed & not evaluated \\
\hline
\end{tabular}

Fig. 8. Recognition correctness

Results obtained are summarized in "Fig. 8 " Above-mentioned table presents promising recognition results of traffic volume and vehicle class.

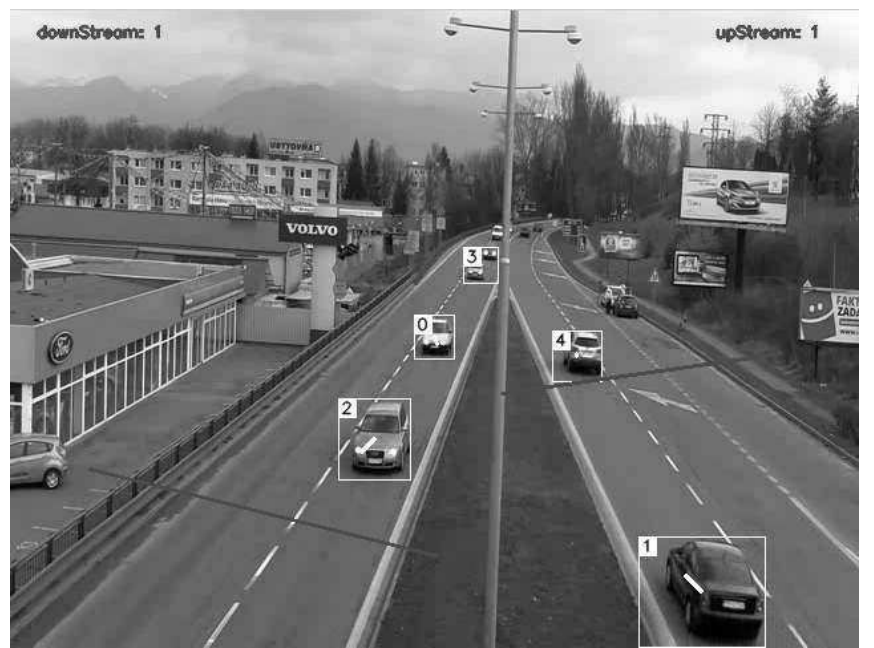

Fig. 9. Visualization of recognition result

Unfortunately vehicle speed was not evaluated because of non-functional microwave speed detector which was intended to be the reference for speed comparation. Sensor average current draw during the test was $440 \mathrm{~mA}$.

\section{ACKNOWLEDGEMENT}

This work was supported by:

- project "Competence Center for research and development in the field of diagnostics and therapy of oncological diseases", ITMS: 26220220153, co-financed from EU sources and European Regional Development Fund.

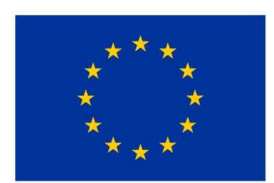

Európska únia

Euróosky fond regionálneho rozvoja

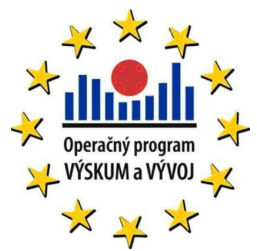

Agentúra

Ministerstva školstva, vedy, výskumu a športu SR pre štrukturálne fondy EÚ

"Podporujeme výskumné aktivity na Slovensku/Projekt je spolufinancovaný zo zdrojov EÚ"

- Faculty of Management Science and Informatics institutional grant.

\section{CONCLUSION}

An approach for the traffic monitoring based on Raspberry Pi single board computer was proposed in this paper. Video signal processing and analysis were proposed with the focus on low power consumption and reliability of the system. This is still far from being final version of traffic monitoring system and there is lot for us to improve. In future we plan to perform further experiments including speed evaluation and testing sensor node in different weather conditions.

\section{REFERENCES}

[1] The Harmful Effects of Vehicle Exhaust, webpage: http://www.ehhi.org/reports/exhaust/summary.shtml [April 19, 2014]

[2] World Health Organization says diesel fumes cause cancer, webpage: http://www.autoblog.com/2012/06/13/world-health-organization-saysdiesel-fumes-cause-cancer [June 19, 2014]

[3] Raspberry Pi, webpage: http://en.wikipedia.org/wiki/Raspberry_Pi [April 20, 2014]

[4] J. G. Proakis and D. G. Manolakis, Digital Signal Processing, New York: MPC, 1992.

[5] J. Miček and O. Karpiš, "Wireless sensor networks - design of smart sensor node," International conference on military Technologies ICMT 2011, Brno, pp. 1109-1116.

[6] O. Karpiš and J. Miček, "Sniper localization using WSN," International conference on military Technologies ICMT 2011, Brno, pp. 1063-1068.

[7] O. Karpiš, "Software actualization in WSN networks," Information and Communication Technologies - International Conference, Žilina, 2012, pp. $51-54$

[8] M. Piccardi Background subtraction techniques: a review. IEEE International Conference on Systems, Man and Cybernetics 4., 2004 pp. 30993104 . 